Supplement of Atmos. Chem. Phys. Discuss., 14, 31009-31038, 2014

http://www.atmos-chem-phys-discuss.net/14/31009/2014/

doi:10.5194/acpd-14-31009-2014-supplement

(C) Author(s) 2014. CC Attribution 3.0 License.

(c) (i)

\title{
Aerosols over Continental Portugal (1978-1993): their sources and an im- pact on the regional climate
}

\author{
A. L. Morozova and I. A. Mironova
}

Correspondence to: A. L. Morozova (annamorozovauc@gmail.com, anna_m@teor.fis.uc.pt) 


\section{Aerosols over Continental Portugal (1978-1993): their sources 2 and an impact on the regional climate}

4 A. L. Morozova ${ }^{1}$ and I. A. Mironova ${ }^{2}$

$5[1]\{$ Center for Geophysics of the University of Coimbra, University of Coimbra, Coimbra, Portugal $\}$

[2]\{ Institute of Physics, St. Petersburg State University, St. Petersburg, Russia

Correspondence to: A. L. Morozova (annamorozovauc@gmail.com, anna_m@teor.fis.uc.pt

\section{Supplemented Material}

\section{$11 \quad 1.1$ Aerosol parameters}

In this study we use the Total Ozone Mapping Spectrometer (TOMS) Aerosol Index (AI) data (http://disc.sci.gsfc.nasa.gov/acdisc/TOMS). The Nimbus-7 satellite with the TOMS instrument onboard was launched on October 1978 and operated continuously for 14.5 years until TOMS failed in May 1993. The TOMS instrument measures the integrated over the atmospheric column amount of the UV light scattered by airborne particles. Data from TOMS can be used to detect the presence of both UV absorbing and non-absorbing (mostly scattering) aerosols in the atmosphere. The UV absorbing aerosols include particles produced by e.g. Saharan dust, forest fires or volcanic eruptions. Non-absorbing aerosols are primarily tiny sulfate and nitrate aerosols produced, mostly, by human activities. Aerosol index is positive when UV absorbing aerosols prevail and AI negative in case of prevailing of non-UV absorbing aerosols. Quantitatively, the TOMS aerosol index AI is defined as (Hsu et al., 1999)

$$
A I=-100\left(\log _{10}\left[I_{\lambda} / I_{\lambda_{0}}\right\rfloor_{\text {meas }}-\log _{10}\left[I_{\lambda} / I_{\lambda_{0}}\right\rfloor_{\text {calc }}\right) \text {, }
$$

where $I_{\text {meas }}$ is the backscattered radiance at wavelengths measured by the TOMS instrument and $I_{\text {calc }}$ is the model calculated radiance assuming an atmosphere of Rayleigh scatterers (pure molecular atmosphere) for two close wavelength $\lambda$ and $\lambda_{0}$ in UV region (Ginoux and Torres, 2003). When UV absorbing aerosols are present in the atmosphere, the spectral contrast $I_{\lambda} / I_{\lambda 0}$ is smaller than predicted by the calculation model, and the equation (S1) produces positive residues. Non-absorbing aerosols produce greater spectral contrast, and thus result in a negative value of AI.

We use the data on AI variations over two locations in the Continental Portugal (see Fig. 1a in the main paper): the site ID 082 over Lisbon $\left(38^{\circ} 46^{\prime} \mathrm{N}, 9^{\circ} 8^{\prime} \mathrm{W}, 105 \mathrm{~m}\right.$ a.s.l.) and the site ID 288 over Penhas Douradas $\left(40^{\circ} 25^{\prime} \mathrm{N}, 7^{\circ} 33^{\prime} \mathrm{W}, 1380 \mathrm{~m}\right.$ a.s.1.). The distance between these sites is about 200 $\mathrm{km}$. The first site corresponds to the urbanized and industrial region; the second site is located in a low populated mountain region which is frequently affected by the forest fire smokes (Pereira et al., 2005) and mineral dust events.

The TOMS instrument on board of the Nimbus-7 satellite provides daily values of AI from 01 November 1978 to 06 May 1993. The series have gaps: 80 days are missed for the site ID 082 (1.5\% of the whole data set length) and 88 days are missed for the site ID 288 (1.7\% of the whole data set length). The TOMS aerosol index is calculated in a way that allowed us to separate days with prevailing of absorbing (e.g. dust, smoke) or scattering (e.g. sulfate aerosols in urban areas) particles. 
1 In this study we used daily data only in one case: to indentify days with Saharan Dust Events (SDE) 2 - see Supplemented Material, Part 1.3.2. For other purposes the monthly, seasonal and annual means

3 of AI have been calculated as described in the main paper (Sec. 2.1).

\section{$4 \quad 1.1 .1$ Aerosol annual cycle.}

5 The annual cycle is clearly present in the AI variations, mainly, due to the well established seasonal 6 changes of the <AIneg> (see Fig. 1 in the main paper and Fig. S1.1a) - more scattering aerosols are 7 seen from October to March, due to the seasonal cycles of nitrate aerosols (see e.g. Calvo et al., 8 2013) and/or other anthropogenic pollutants. During the autumn-winter cold period there is an 9 additional input of soot from the domestic heating and, probably, an increase of the local traffic due 10 to the rainy weather conditions (Pereira et al., 2012, Querol et al., 1998).
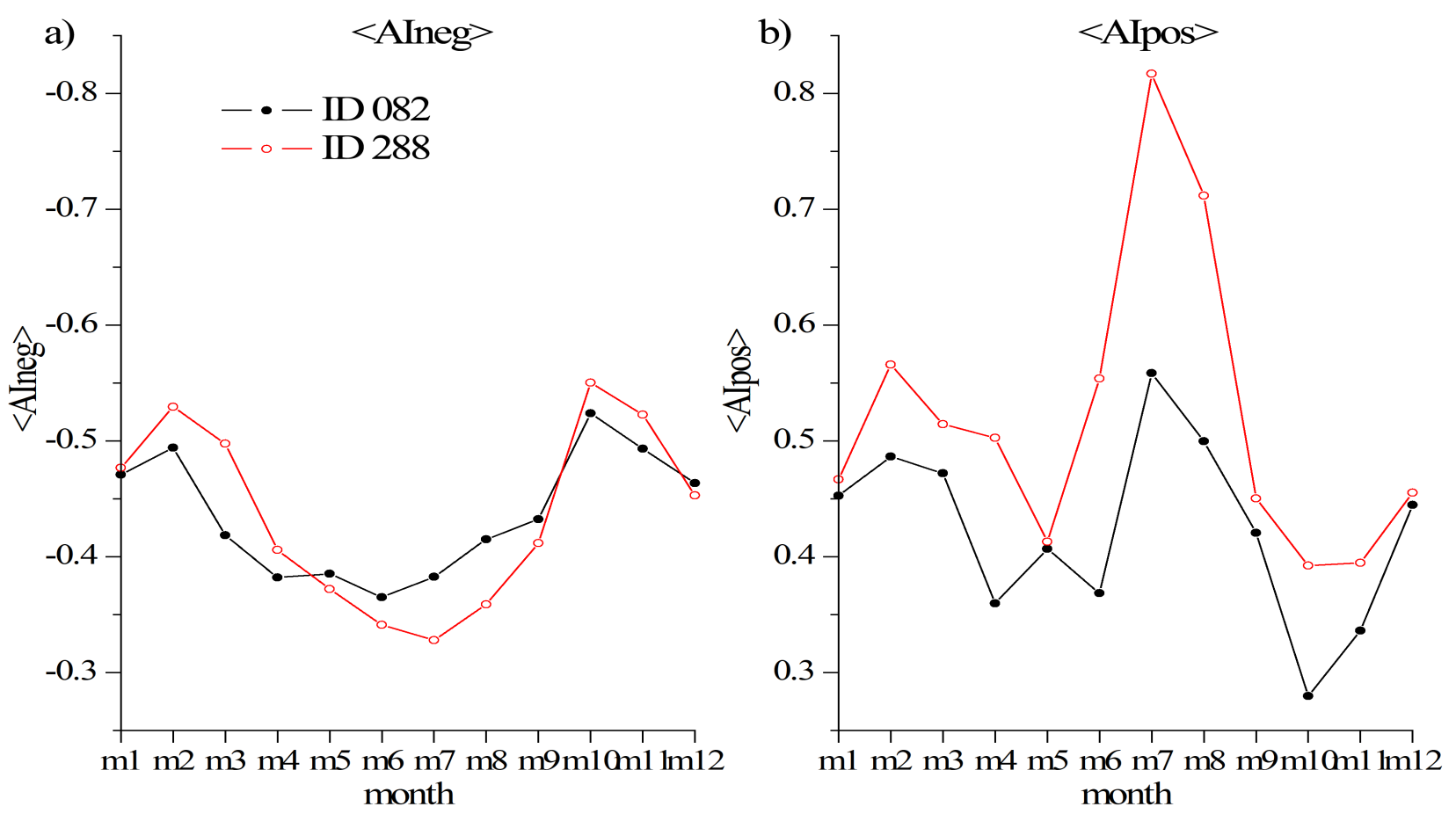

13 Figure S1.1. Annual cycle of <AIneg> (a) and <AIpos> (b) for the sites ID 082 (black lines with 14 filled dots) and ID 288 (red lines with open dots) for $1979-1992$ period. Please note that Y-axis on 15 (a) is inverted.

The <AIpos> shows a tendency to bimodal seasonal variations having higher values in July-August with a second (lower) maximum in February-March (Fig. S1.1b). This bimodality is in an agreement with the in-situ measurements made in Évora, Portugal $\left(38.5^{\circ} \mathrm{N}, 7.9^{\circ} \mathrm{W}, 300 \mathrm{~m}\right.$ a.s.1.) during the 2002-2008 period (Pereira et al., 2008, 2011). The summer peak is related to the wildfire smokes and intensive SDE events, and the winter maximum is mostly due to the combined effect of local traffic and increased emission from heating sources.

\section{1.1.2 Spatial correlation between the sites.}

24 The spatial correlation for <AIpos> and <AIneg> series between the two sites is more or less strong 25 (Fig. S1.2). The highest correlations are between the $\langle$ AI $\rangle$ series. The correlations coefficients for 
the <AIpos> series are higher for the monthly series, and for the <AIneg> series are higher for the 2 annual series.
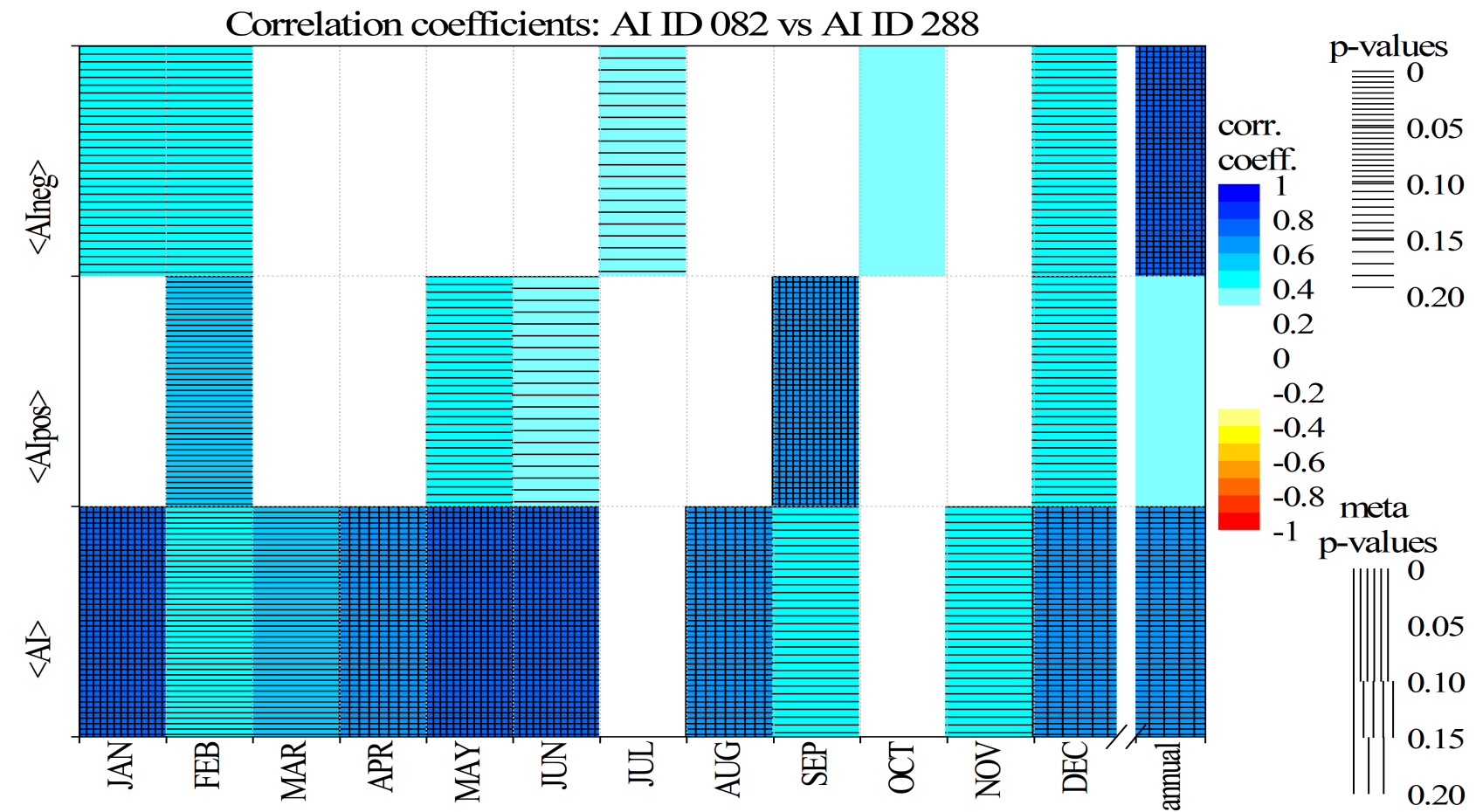

Figure S1.2. Correlation coefficients ( $r$ ) between the AI indices measured at two aerosol sites ID 082 and ID 288. Only correlation coefficients $|r| \geq 0.3$ are shown. The statistical significances for singular (p-values) and multiple (meta p-values) comparisons are shown by shading.

\subsection{Atmospheric parameters}

Two sets of climatic data were used in this study containing the monthly and annual means of the temperature parameters (the minimum (Tmin), maximum (Tmax) and average (averT) temperatures, and the daily temperature range $(D T R)$ ), the accumulated precipitation amount (precip), the mean atmospheric pressure at station level $(p)$ and the sunshine duration $(S s h D)$. These series belong to the Geophysical Institute of University of Coimbra ("IGUC series") and the Geophysical Institute of Instituto Dom Luiz of University of Lisbon ("IGIDL series"). Both locations are shown on the map in Fig. 1a of the main paper.

These series have different length, but all of them are available for the studied period. The temperature series already have passed through the homogenization procedure and are considered free from the significant artificial homogeneity breaks (see Morozova and Valente (2012) for details). The other digitalized series were checked for OCR errors and misprints. Afterward, the homogeneity of these series was analysed using standard homogeneity tests (same as used in Morozova and Valente, 2012), and a number of probably artificial homogeneity breaks were found. Fortunately, none of these breaks took place during the relatively short studied period. Therefore, these series were used without any correction.

The effect of the aerosol variations on atmospheric conditions were studied separately for two sites (see Section 4 of the main paper): the IGIDL series were used in pair with AI data from the site ID 082, and the IGUC series were used in pair with the AI series from the site ID 288. Since the distance between the aerosol detection site and the meteorological station is about $74 \mathrm{~km}$ in case of 
the site ID 288 and therefore is quite large, we compared the data from IGUC with the data from the meteorological station at Pehnas Douradas (located very close to the AI site ID 288) available at Global Historical Climatology Network data base (http://www.ncdc.noaa.gov/ghcnm/, station ID 8568). This dataset contains data on monthly means of daily mean temperature, pressure recalculated to the sea-level and precipitation amount. These series are quite short, fragmented and do not fully cover the AI measurement period. However, they are highly correlated with the corresponding IGUC series as is seen in Fig. S1.3. Therefore, we decided to use only IGUC series that have no gaps, for which we can obtain all metadata information and perform all necessary homogeneity tests.

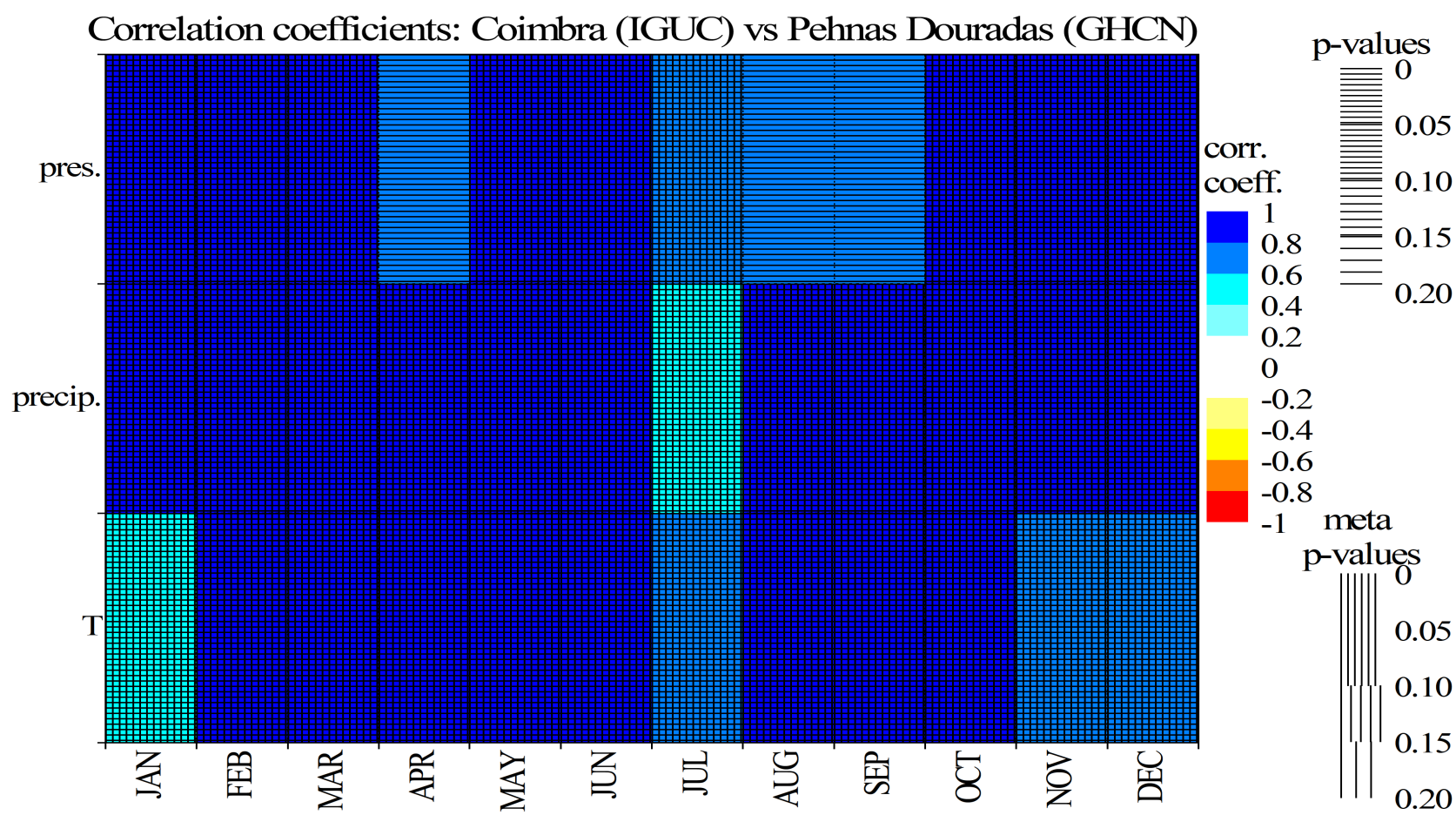

Figure S1.3. Correlation coefficients $(r)$ between the atmospheric parameters measured in Coimbra (IGUC series) and Pehnas Douradas (Global Historical Climatology Network series). Only correlation coefficients $|r| \geq 0.3$ are shown. The statistical significances for singular ( $p$-values) and multiple (meta p-values) comparisons are shown by shading.

The climatic conditions in Lisbon and Coimbra are quite similar but not identical. The lowest correlation coefficient between the series from these two stations are found for the precipitation amount and DTR in August (0.16 and 0.44, correspondingly) and April (0.34 and 0.25, correspondingly) - see Fig. S1.4. Other series of atmospheric parameters from the IGUC and IGIDL have correlation coefficients in the range from 0.5 to 0.998 with low p-values and meta p-values. 


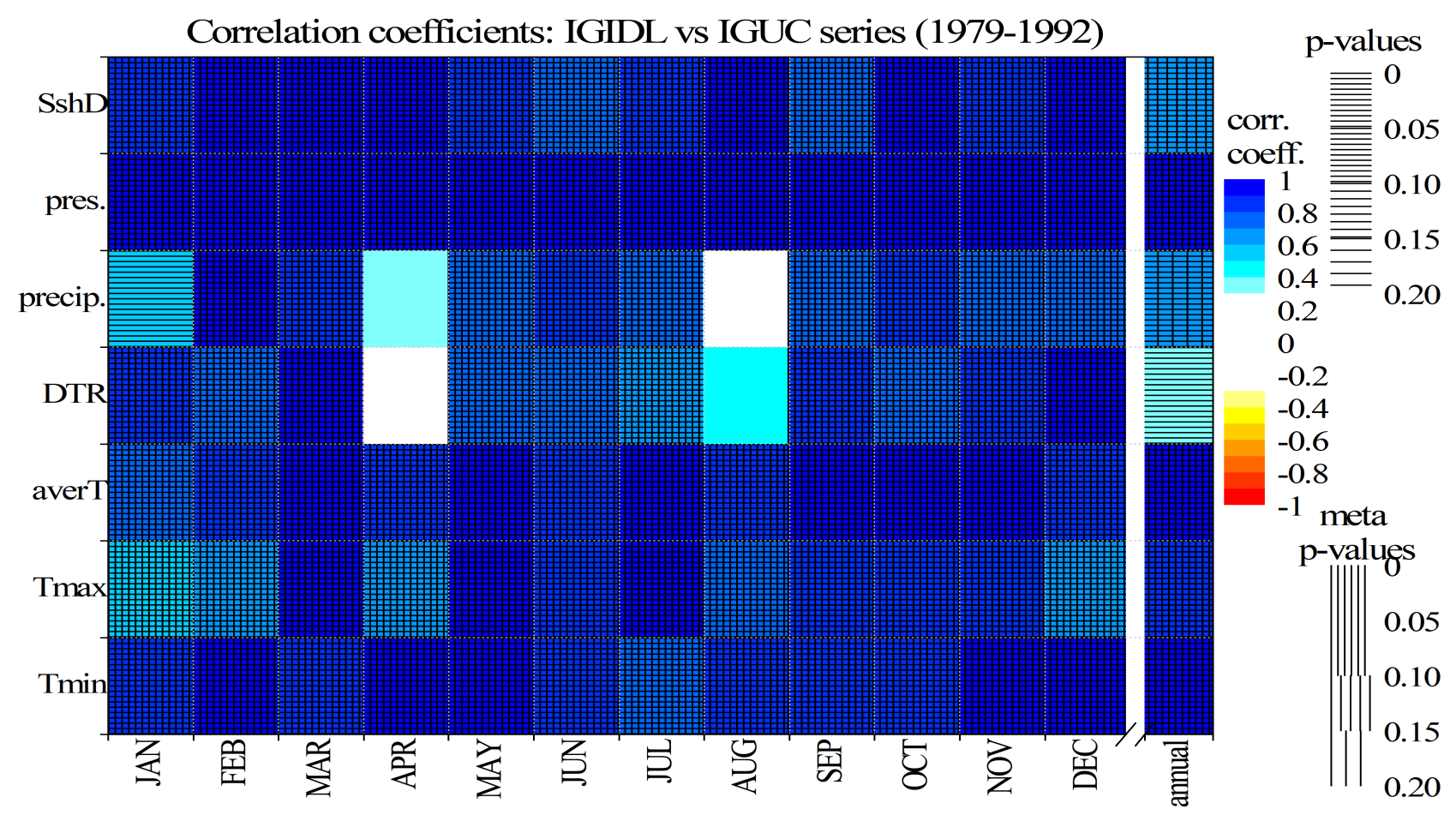

2 Figure S1.4. Correlation coefficients $(r)$ between the atmospheric parameters measured in Coimbra 3 (IGUC series) and Lisbon (IGIDL series). Only correlation coefficients $|r| \geq 0.3$ are shown. The 4 statistical significances for singular (p-values) and multiple (meta p-values) comparisons are shown 5 by shading.

\subsection{Aerosol sources}

$8 \quad 1.3 .1$ Volcanoes.

9 The stratospheric aerosol optical thickness (AOT) at $550 \mathrm{~nm}$ for Northern Hemisphere from the 10 GISS climate simulation (http://data.giss.nasa.gov/modelforce/strataer) is used as a proxy for the 11 volcanic aerosol content changes (Sato et al., 1993 and Bourassa and Robock, 2012). During the 12 studied period four volcanic eruptions with the volcanic emissivity index VEI $>4$ took places 13 (numbered in Fig. 2c of the main paper):

14 1. 1980 March - Mt. St. Helens, tropospheric eruption

15 2. 1982 March-April - El Chichon, stratospheric eruption

16 3. 1991 June \& August - Pinatubo, stratospheric eruption

17 4. 1991 August-October - Mt. Hudson, stratospheric eruption

18 These eruptions, except the first one, deposited a significant load of sulfate aerosols to stratosphere 19 over the globe. However, during the years following the eruptions the amount of the absorbing 20 particles in a zone around $40 \mathrm{~N}$ latitude did not increased as dramatically as in regions around the 21 equator (see e.g. Fig. 3 in Torres et al., 2002).

\section{1.3.2 Saharan Dust Events (SDE).}

23 In this work we identified SDE as described in Barkan et al. (2005) and Varga et al. (2013). The 24 Saharan dust event is defined as a day when a standardized AI ( $\mathrm{AI}_{\text {st, }}$ see Eq. S2) is not less than 3.5. 
1 The daily AI series were standardized separately for each year to reduce their annual means $\left(A I_{\text {mean }}\right)$

2 to 0 and standard deviations $\left(\sigma_{A I}\right)$ to 1 (see Barkan et al., 2005).

$3 A I_{s t}=\left(A I-A I_{\text {mean }}\right) / \sigma_{A I}$,

4 Considering that we did not used satellite images for the SDE identification, we cannot guarantee

5 that all the events detected by above mentioned method are the real SDEs. We also could have

6 missed some events. To test our SDE list, we compared monthly/annual sums of our SDEs for both

7 Portuguese sites with similar published data for regions more or less close to Portugal:

8 1. number of the Saharan dust events in July from Brakan et al. (2005) - Italy;

9 2. annual sums of the SDE from Rogora et al. (2004) - NW Italy;

10 3. annual sums of the SDE from Varga et al. (2013) - Carpathian Basin.

11 The results of the comparison are shown in Fig. S1.5b-d. The number of dust events detected by us 12 for the site ID 288 correlate well with other data. Correlation coefficients are 0.48 and 0.56 for 13 annual data and 0.89 for monthly ( $\mathrm{p}$-values for all correlation coefficients a lower than 0.01 ). The 14 number of the SDEs for the site ID 082 shows a very weak (if any) correlation with other series. 15 Figure S1.5a shows as well the annual cycle for the monthly sums of the SDEs detected in our study 16 for both locations. As expected, July and August are months of the highest frequency of SDEs.

17 The sites ID 082 and ID 288 were analysed separately. During the studied period 28 SDEs were 18 found for the site ID 082 and 45 SDEs were found for the site ID 288 (see Fig. 2d of the main paper). 19 As was previously shown by different studies (see e.g. Moulin et al., 1998, Barkan and Alpert, 2008 or Israelevich et al., 2012), most frequent routs for the dust intrusions coming from Sahara to the west part of the Iberian Peninsula pass through the west part of the Mediterranean sea and Spain or along a west-east line after over passing the North Atlantic Ocean (e.g. Pereira et al. 2008, 2011). Thus, a greater number of SDEs for the site ID 288 is due to its more north-east position. This hypothesis is confirmed by the fact that in cases when the SDE is observed on both sites more or less simultaneously, on the site ID 288 it took place 1-3 days earlier than on the site ID 082. High daily values of the <AIpos> during the detected SDEs contribute to the increase of monthly means of the $<$ AIpos>. Months with a very high content of absorbing aerosols (<AIpos $>\geq 0.8$ for averaged data) are months with at least three SDEs. There are two exceptions (February 1985 and September 1988). During these months only two SDEs took places, but the monthly <AIpos> is over 0.8 . In both cases one of the pair of SDEs was an extremely strong event. The variations of the monthly mean <AIpos> index averaged over two Portuguese locations increase together with the total monthly number of dust events are shown in Fig. S1.6).

34 


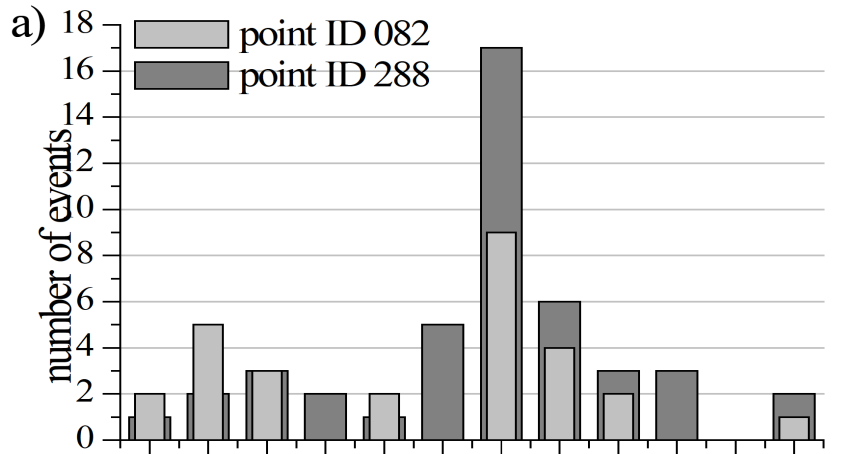

$\mathrm{m} 1 \mathrm{~m} 2 \mathrm{~m} 3 \mathrm{~m} 4 \mathrm{~m} 5 \mathrm{~m} 6 \mathrm{~m} 7 \mathrm{~m} 8 \mathrm{~m} 9 \mathrm{~m} 10 \mathrm{~m} 11 \mathrm{~m} 12$

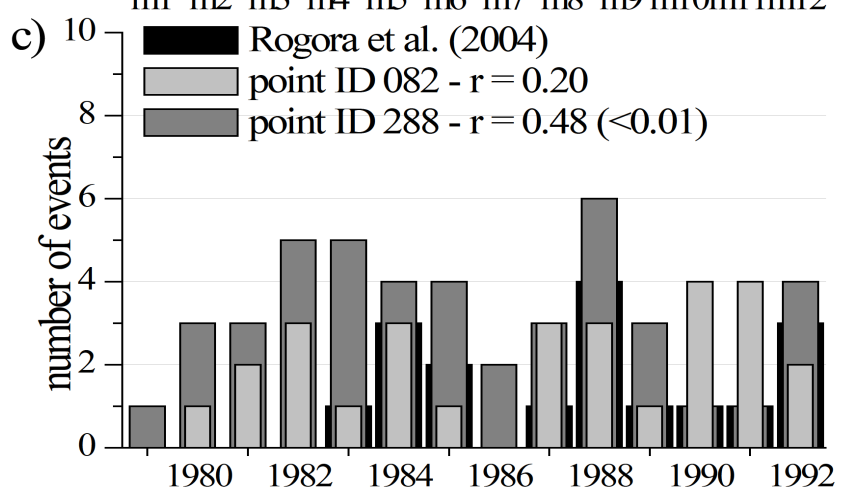

b)
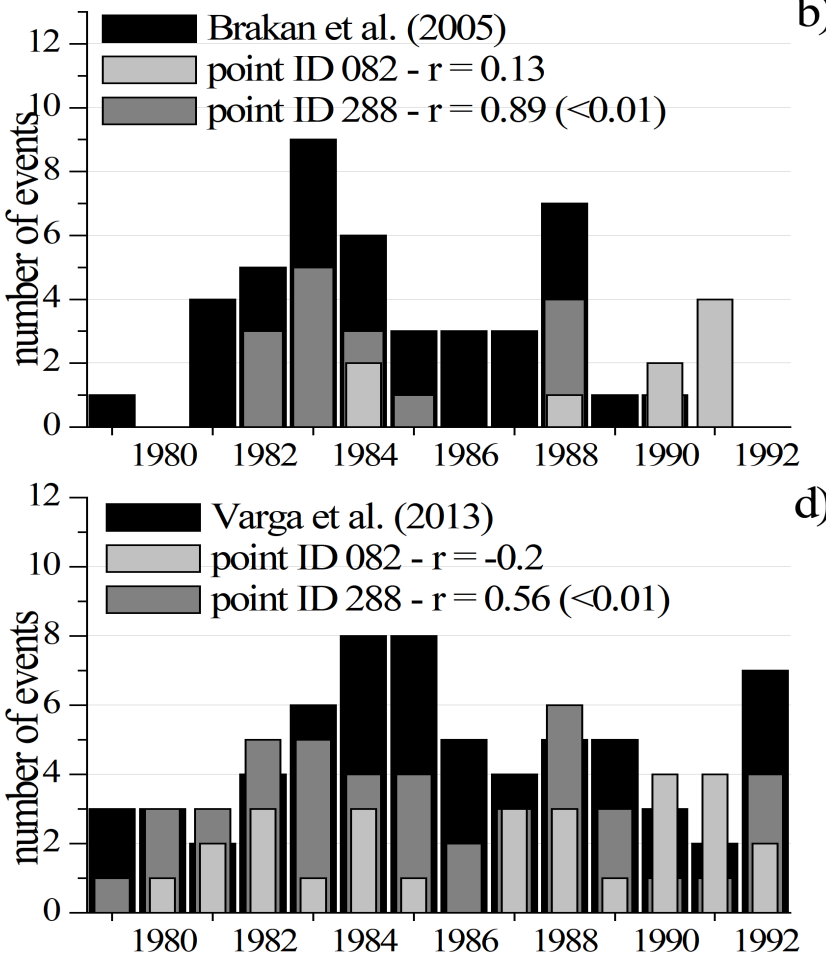

d)

Figure S1.5. (a) Annual cycle of the monthly number of SDE for Portuguese sites ID 082 and ID 288. (b-d) Variations of the monthly (b) and annual (c-d) SDE number for two Portuguese sites compared to the equivalent data from other studies The correlation coefficients $r$ between the monthly/annual sums of the SDE events detected by us and by other authors are shown with p-values in brackets.

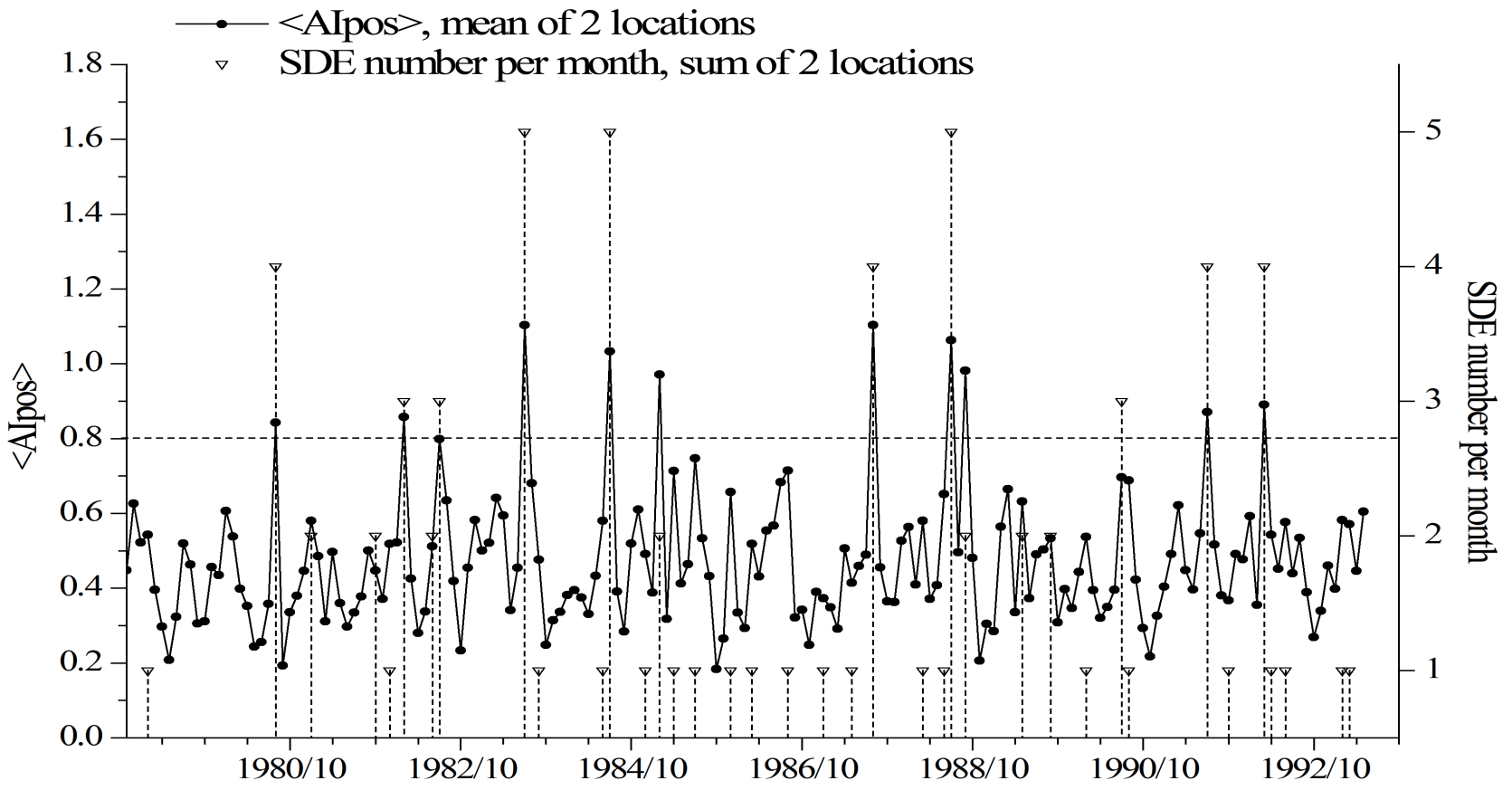

$8 \quad$ Figure S1.6. Series of monthly <AIpos> (a mean for two sites ID 082 and ID 288) - lines with dots 9 - and a total number of SDE per month for the same sites - triangles. 


\section{$1 \quad 1.3 .3$ Forest fires.}

2 Aerosols originated from the forest fire are very common for Portugal during the hot and dry summer 3 months (from June to September) (see e.g. Pereira et al., 2008 and Obregón et al., 2012). The total 4 burned area (BA) data from the Portuguese Institute for the Conservation of the Nature and Forests 5 (Instituto da Conservação da Natureza e das Florestas, ICNF,) are used in our study as a proxy for 6 this type of aerosols (like e.g. black carbon, soot and smoke).

\section{1.3.4 Pollution.}

8 In this work we use the data from the European Monitoring and Evaluation Programme (EMEP) 9 database (http://www.emep.int/, specifically, EBAS database http://ebas.nilu.no/) which contain the 10 monthly mean values of $\mathrm{SO}_{2}$ (in $\mu \mathrm{g} \mathrm{S} / \mathrm{m}^{3}$ ) for the five following Portuguese stations (two in the 11 northern, one in the middle and two in the southern parts of the country) measured from August 121979 to December 2009:

13 1. Braganca $\left(41^{\circ} 49^{\prime} \mathrm{N}, 6^{\circ} 46^{\prime} \mathrm{W}, 690 \mathrm{~m}\right.$ a.s.1.)

14 2. Viana do Castelo ( $41^{\circ} 42^{\prime} \mathrm{N}, 8^{\circ} 48^{\prime} \mathrm{W}, 16 \mathrm{~m}$ a.s.1.)

15 3. Monte Velho ( $38^{\circ} 05^{\prime} \mathrm{N}, 8^{\circ} 48^{\prime} \mathrm{W}, 43 \mathrm{~m}$ a.s.1.)

16 4. Foia $\left(37^{\circ} 19^{\prime} \mathrm{N}, 8^{\circ} 54^{\prime} \mathrm{W}, 902 \mathrm{~m}\right.$ a.s.1. $)$

$17 \quad$ 5. Faro $\left(37^{\circ} 01^{\prime} \mathrm{N}, 7^{\circ} 58^{\prime} \mathrm{W}, 8 \mathrm{~m}\right.$ a.s.1.).

18 The data series contain significant gaps (14\% of the whole data set length), and measurement time intervals are different for different stations. We calculated the mean series using the data from all five series with the linearly interpolation of the gaps.

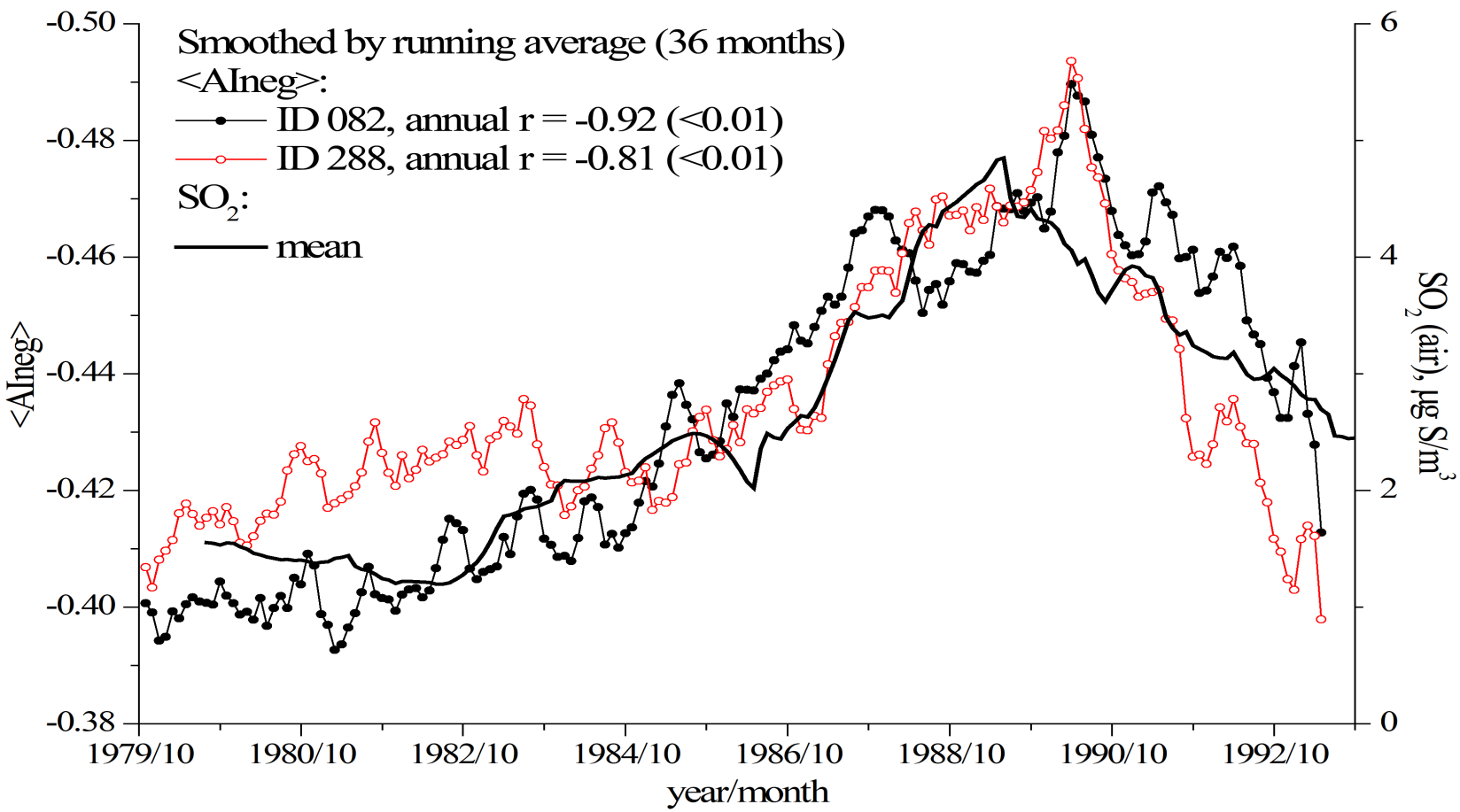

Figure S1.7. Monthly variations of $\mathrm{SO}_{2}$ (thick black line) and aerosol indices <AIneg> for two sites: ID 082 (black lines filled dots) and ID 288 (red lines open dots) smoothed by the 36-months running averaging. Correlation coefficients $(r)$ are calculated between the AI and sulfate series ( $p$-values are shown in brackets). Please note inverted left $Y$ axis. 
1 The correlations between the <AIneg> and $\mathrm{SO}_{2}$ variations became even much stronger when trends of these two parameters are studied. For example, the comparison of the monthly series of the $\mathrm{SO}_{2}$ and the <AIneg> smoothed by the running averaging procedure (window of 36 months) - Fig. S1.7 shows that the satellite measured <AIneg> series follows the ground measured sulfate content data with probably a lag of about 5-10 months.

\section{References}

8 Barkan, J., Alpert, P., Synoptic patterns associated with dusty and non-dusty seasons in the Sahara.

9 Theoretical and Applied Climatology, 94, 3-4, 153-162, 2008.

10 Barkan, J.; Alpert, P.; Kutiel, H.; Kishcha, P.: Synoptics of dust transportation days from Africa toward Italy and central Europe. JGR: Atmospheres, Volume 110, Issue D7, CiteID D07208, 2005.

Bourassa, A.E., A. Robock, et al. Large volcanic aerosol load in the stratosphere linked to Asian monsoon transport. Science 337, 78-81, 2012.

14 Calvo, A.I., Alves, C., Castro, A., Pont, V., Vicente, A.M., Fraile, R.: Research on aerosol sources and chemical composition: Past, current and emerging issues, Atmos. Res. 120-121, 1-28, 2013.

Catry, F.X., Rego, F.C., Bação, F.L., Moreira, F.: Modeling and mapping wildfire ignition risk in Portugal. International Journal of Wildland Fire 18, 921-931, 2009. http://dx.doi.org/10.1071/WF07123

19 Fiol, L. A., Fornós, J. J., Gelabert, B., Guijarro, J. A. Dust rains in Mallorca (Western

20 Mediterranean): Their occurrence and role in some recent geological processes. Catena, 63, 1, 64-84, 212005.

22 Ginoux, P., Torres, O.: Empirical TOMS index for dust aerosol: Applications to model validation 23 and source characterization, JGR: Atmospheres (1984-2012), 108(D17), 4534, 24 doi:10.1029/2003JD003470, 2003.

25 Hsu, N. C., Herman, J. R., Torres, O., Holben, B. N., Tanre, D., Eck, T. F., Smirnov, A., Chatenet, 26 B., and Lavenu, F.: Comparisons of the TOMS aerosol index with Sunphotometer aerosol optical 27 thickness: Results and applications, J. Geophys. Res., 104, 6269-6279, 28 doi:http://dx.doi.org/10.1029/1998JD20008610.1029/1998JD200086, 1999.

29 Israelevich, P., Ganor, E., Alpert, P., Kishcha, P., Stupp, A.: Predominant transport paths of Saharan dust over the Mediterranean Sea to Europe. J. Geophys. Res.: Atmos., 117, D2, CiteID D02205, 2012 .

Morozova, A. L. and Valente, M. A.: Homogenization of Portuguese long-term temperature data series: Lisbon, Coimbra and Porto, Earth Syst. Sci. Data, 4, 187-213, 2012.

Moulin, C., Lambert, C. E., Dayan, U., Masson, V., Ramonet, M., Bousquet, P., Legrand, M., Balkanski, Y. J., Guelle, W., Marticorena, B., Bergametti, G., Dulac, F., Satellite climatology of African dust transport in the Mediterranean atmosphere. JGR: Atmospheres, 103, D11, 13,137$3713,144,1998$.

38 Obregón, M.A., Pereira, S., Wagner, F., Serrano, A., Cancillo, M.L., Silva, A. M.: Regional 39 differences of column aerosol parameters in western Iberian Peninsula, Atmospheric Environment, $40 \quad 62,208-219,2012$. 
1 Pereira, M.G., Trigo, R.M., da Camara, C.C., Pereira, J.M.C., Leite, S.M.: Synoptic patterns 2 associated with large summer forest fires in Portugal, Agricultural and Forest Meteorology, 129, 1-2, 3 11-25, doi: 10.1016/j.agrformet.2004.12.007, 2005.

4 Pereira, S., Wagner, F., Silva, A.M.: Scattering properties and mass concentration of local and long5 range transported aerosols over the South Western Iberia Peninsula, Atmos. Environ., 42, 33, 7623$67631,2008$.

7 Pereira, S.N., Wagner, F., Silva, A.M.: Seven years of measurements of aerosol scattering properties, 8 near the surface, in the southwestern Iberia Peninsula, Atmospheric Chemistry and Physics, 11, 1, $9 \quad 17-29,2011$.

10 Pereira, S.N., Wagner, F., Silva, A.M.: Long term black carbon measurements in the southwestern 11 Iberia Peninsula, Atmos. Environ., 57, 63-71, 2012.

12 Querol, X., Alastuey, A., Puicercus, J.A., Mantilla, E., Miro, J.V., Lopez-Soler, A., Plana, F., 13 Artiñano, B.: Seasonal evolution of suspended particles around a large coal-fired power station. 14 particulate levels and sources, Atmospheric Environment, 32, 11, 1963-1978, 1998.

15 Rogora, M., Mosello, R., Marchetto, A., Long-term trends in the chemistry of atmospheric 16 deposition in Northwestern Italy: the role of increasing Saharan dust deposition, Tellus B, 56, 5, 42617 434, 2004.

18 Sato, M., J.E. Hansen, M.P. McCormick, and J.B. Pollack. Stratospheric aerosol optical depth, 185019 1990. J. Geophys. Res. 98, 22987-22994, 1993

20 Torres, O., Bhartia, P. K., Herman, J. R., Sinyuk, A., Ginoux, P., Holben, B., A.: Long-Term Record 21 of Aerosol Optical Depth from TOMS Observations and Comparison to AERONET Measurements. 22 JGR, 59, 3, 398-413, 2002.

23 Varga, G., Kovács, J., Újvári, G.: Analysis of Saharan dust intrusions into the Carpathian Basin 24 (Central Europe) over the period of 1979-2011. Global and Planetary Change, 100, 333-342, 2013.

25 Wang C.: Impact of anthropogenic absorbing aerosols on clouds and precipitation: A review of 26 recent progresses, Atmos. Res., 122, 237-249, 2013. 


\section{Part 2. Sunshine duration variations}

2 Figure S2.1 shows the correlation coefficients between the variations of the sunshine duration and 3 other atmospheric parameters. As one can see, $S s h D$ is strongly anti-correlates with precipitations 4 amount (a proxy for the cloud amount) and correlate with the atmospheric pressure (except summer 5 dry months). In turn, the $D T R$ series are affected by the $S s h D$ variations: the decrease of the sunshine 6 duration coincides with the decrease of the daily temperature range. This results, most probably, 7 from the decrease of the day-time temperature (Tmax) due to the lower amount of solar radiation. 8 The correlation between the $S s h D$ and the atmospheric pressure is strong and statistically significant 9 only during cold and wet season from October to March which is a sign of the Atlantic cyclones' effect (Miranda et al., 2002).

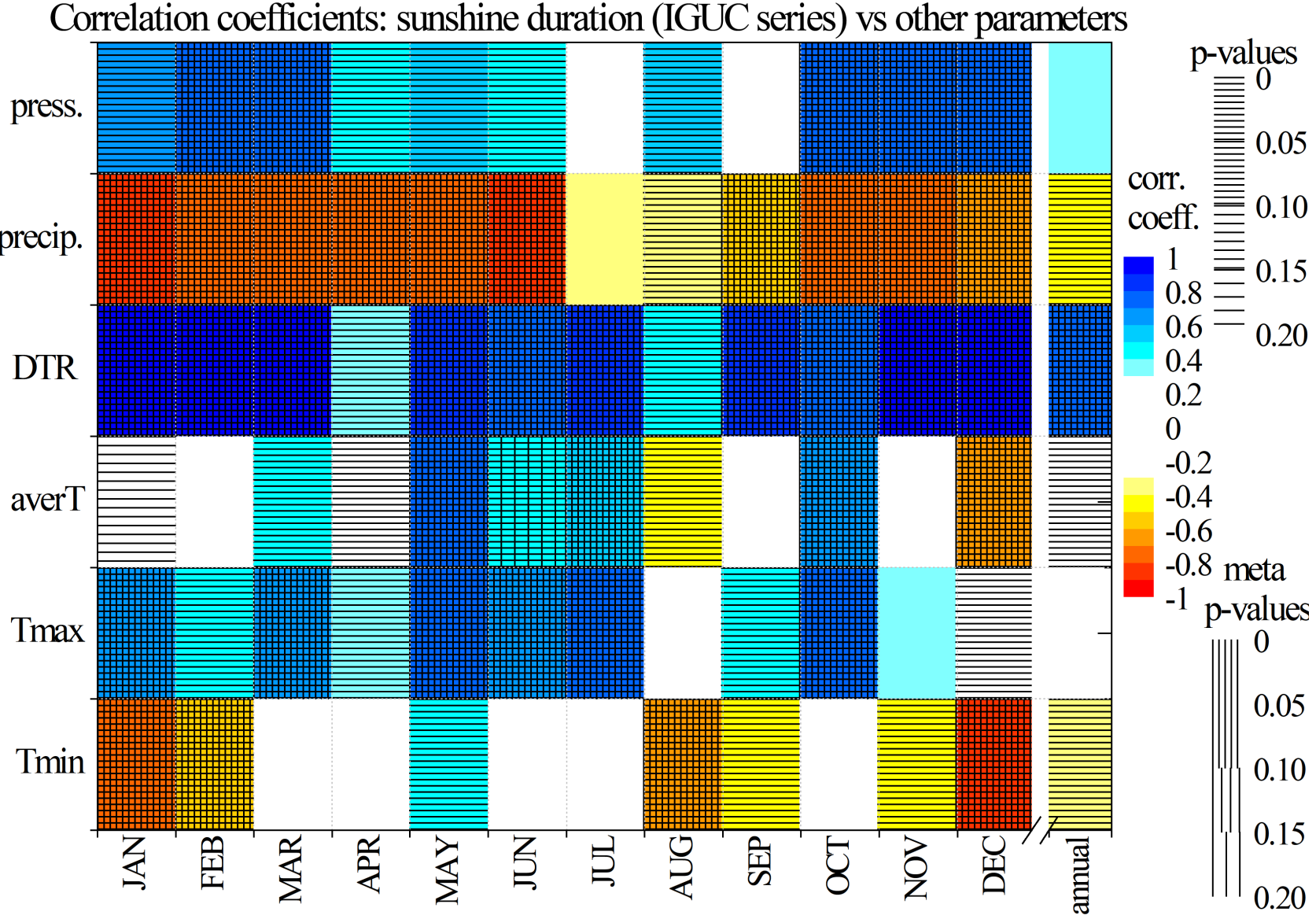

Figure S2.1. Correlation coefficients $(r)$ between the SshD and other atmospheric parameters measured in Coimbra (IGUC series). Only correlation coefficients $|r| \geq 0.3$ are shown. The statistical significances for singular (p-values) and multiple (meta p-values) comparisons are shown by shading.

\section{References}

19 Miranda, P., Coelho, F. E. S., Tomé, A. R., Valente, M. A., Carvalho, A., Pires, C., Pires, H. O., 20 Pires, V. C., Ramalho, C.: 20th century Portuguese climate and climate scenarios, in: Climate 21 Change in Portugal. Scenarios, Impacts and Adaptation Measures-SIAM Project, Santos FD, 22 Forbes K, Moita R (Eds), Gradiva Publishers, Lisbon, 23-83, 2002. 